\title{
Centro de convivência de idosos: uma abordagem de estimulaçáo cognitiva e psicossocial
}

\author{
Nathalia Barros de Andradea ${ }^{\mathrm{a}}$, Mariana Boaro Fernadez Canon ${ }^{\mathrm{a}}$, Camilla Lima Zugman, \\ Thalita Gonçalves Ayres ${ }^{b}$, Mariana Graziella Ide ${ }^{b}$, Marcia Maria Pires Camargo Novellic

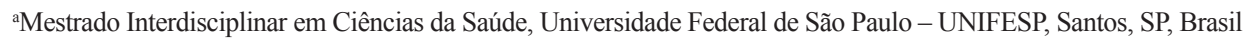

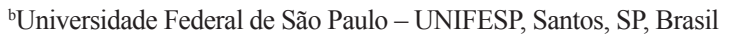 \\ 'Mestrado Interdisciplinar em Ciências da Saúde, Departamento de Gestão e Cuidado em Saúde, \\ Universidade Federal de São Paulo - UNIFESP, Santos, SP, Brasil
}

\begin{abstract}
Resumo: Objetivou-se descrever as atividades desenvolvidas em um centro de convivência de idosos e investigar a qualidade e os efeitos delas através da percepção dos participantes. Metodologia: A oficina "Deu Branco" foi um grupo aberto de estimulação cognitiva e psicossocial realizado no primeiro semestre de 2010 em um centro de convivência para terceira idade. Foram desenvolvidos 13 encontros com aproximadamente uma hora de duração cada e participaram das atividades em média oito idosos por oficina. Ao término dos encontros utilizou-se, como método de avaliação, um questionário semiestruturado, contendo questões a respeito da qualidade de cada atividade realizada e da percepção dos participantes em relação a mudanças cognitivas e psicossociais com a participação na oficina, além das observações clínicas realizadas pelas estagiárias do desempenho dos participantes. Resultados e discussão: As atividades realizadas foram qualificadas pelos participantes entre boa, muito boa e excelente, assim como foram relatadas melhoras no desempenho da memória por $100 \%$ dos participantes. Segundo a percepção clínica das estagiárias, as atividades atividades propostas contribuíram para melhoria do desempenho cognitivo, psicológico e social dos participantes durante os encontros. Conclusão: A experiência de grupo mostrou-se como um bom recurso terapêutico ocupacional de promoção e prevenção de saúde para população idosa, além de uma possibilidade de intervenção cognitiva precoce junto a essa população.
\end{abstract}

Palavras-chave: Terapia Ocupacional, Envelhecimento, Memória, Promoção da Saúde, Lazer.

\section{Community center for the elderly: an approach to cognitive and psychosocial stimulation}

\begin{abstract}
Objective: To describe the activities in the workshop "Deu Branco" and investigate their quality and effect through the perception of participants. Methodology: The workshop "Deu Branco" was an open group of cognitive and psychosocial stimulation held in a Community Center for the elderly in the first half of 2010. The meetings last approximately one hour and had an average of eight participants. When the meetings ceased, the participants were asked to respond to a semi-structured questionnaire, developed by the interns, regarding the quality of each activity and their perception of cognitive improvement with the participation in the workshop; in addition to the questionnaire, the interns performed clinical observations regarding the performance of participants. Results and discussion: The activities were rated by the participants as good, very good, or excellent. Improvement in memory performance was reported by all subjects. According to the clinical perception of the interns, the activities contributed to improve the cognitive, psychological and social performance of the participants during the meetings. Conclusion: The open group experience proved to be a good resource of occupational therapy to promote health for the elderly, as well as a possibility of early cognitive intervention for this population.
\end{abstract}

Keywords: Occupational Therapy, Elderly, Memory, Health Promotion, Leisure.

Autor para correspondência: Marcia Maria Pires Camargo Novelli, Departamento de Gestão e Cuidados em Saúde, Instituto de Saúde e Sociedade, Universidade Federal de São Paulo, Campus Baixada Santista, Rua Silva Jardim, 136, Vila Mathias, CEP 11015-020, Santos, SP, Brasil, e-mail: mnovelli@uol.com.br

Recebido em 17/8/2011; $1^{\text {a }}$ Revisão em 17/11/2011; 2a Revisão em 16/2/2012; Aceito em 7/3/2012. 


\section{Introdução}

O crescente aumento da população idosa não está sendo acompanhado pela melhoria na qualidade de vida, impedindo assim que as pessoas tenham um envelhecimento bem-sucedido, apresentando para a sociedade e para os órgãos governamentais desafios médicos e socioeconômicos próprios do envelhecimento populacional (PAPÁLEO NETTO, 2007).

Atualmente, no Brasil, os idosos representam 21 milhóes de pessoas, sendo, portanto 11,3\% da populaçáo (INSTITUTO..., 2010). A cidade de Santos é considerada uma das cidades que proporcionam melhor qualidade de vida ao idoso, recebendo, assim, um grande contingente de pessoas com 60 anos ou mais, apresentando $18 \%$ da população com essa faixa etária (CARTILHA..., 2011).

Dentre a rede de serviços públicos para atender essa populaçáo estấo os Centros de Convivência para a Terceira Idade (Cecoms), espaços idealizados para prevenir o isolamento social, com atividades que estimulam e preservam o bem-estar físico e emocional dessa população, valorizando a convivência, as relaçóes familiares e comunitárias (SANTOS, 2010).

De acordo com a portaria 73 de 2001, do Ministério da Saúde, o atendimento nos Cecoms consiste no fortalecimento de atividades associativas, produtivas e promocionais, contribuindo para a autonomia, o envelhecimento ativo e saudável. Nesses espaços são desenvolvidas atividades planejadas e sistematizadas, ações de atenção ao idoso, de forma a elevar a qualidade de vida, promover a participação, a convivência social, a cidadania e a integração intergeracional (BRASIL, 2001).

Nesse contexto, a Terapia Ocupacional (TO) tem como papel o desenvolvimento de trabalhos comunitários de promoção à cidadania e de lideranças, prevenção de incapacidades, adaptaçáo ambiental e programas de educação para a saúde (MELLO, 2007) através do uso de atividades que podem ser propostas individualmente ou em grupo.

A capacidade de desempenho ocupacional dos indivíduos é a ênfase da terapia ocupacional e sua atuação tem como objetivo geral promover a independência e autonomia nas áreas de ocupaçáo, sendo elas atividades básicas da vida diária (ABVD), atividades instrumentais da vida diária (AIVD), descanso e sono, educação, trabalho, lazer e participação social.

Para execuçáo dessas atividades são requeridas funçóes e habilidades, que em TO, são chamados de componentes de desempenho. Dentre os componentes de desempenho, a cognição tem sido considerada essencial para a realização de atividades em todas as esferas da vida social e interpessoal, trabalho, lazer e atividades da vida diária (ABREU; TAMAI, 2006).

As atividades com grupos de terceira idade são consideradas formas de intervenção para manter e/ou alcançar uma vida saudável e integrada socialmente, propiciando aos participantes uma melhor qualidade de vida e ajudando-os a manter a independência (LIMA; PASETCHNY, 1998).

Diante desse cenário evidencia-se a necessidade da criação e manutenção de grupos de atividades para idosos, como uma forma de estimular os componentes de desempenho, ampliar o repertório de atividades, melhorar a qualidade de vida e consequentemente promover a saúde e a sua prevenção.

O presente artigo tem por objetivo descrever as atividades desenvolvidas na oficina Deu Branco, que fez parte do programa de estágio profissionalizante na área de gerontologia do curso de Terapia Ocupacional da Universidade Federal de São Paulo, e analisar a qualidade e os efeitos das atividades desenvolvidas através da percepção dos participantes.

\section{Materiais e métodos}

A terapia ocupacional em uma proposta de atendimento grupal visa além do processo de socialização e de qualidade de vida contribuir para a melhoria da independência, autonomia, participação e das capacidades cognitivas - atenção, concentração, memória, resolução de problemas, orientação temporal e espacial e funçóes executivas - através de atividades lúdicas.

Com esse objetivo a oficina Deu Branco foi proposta e realizada no Centro de Convivência Vida Nova, localizado no bairro José Menino, do município de Santos, SP. Fez parte do programa de estágio profissionalizante na área de gerontologia no curso de Terapia Ocupacional da Universidade Federal de São Paulo, Campus Baixada Santista. Foi elaborada e coordenada por cinco estagiárias que estavam cursando o sétimo termo (quarto ano) e teve a supervisáo de uma docente do curso no período de fevereiro a junho de 2010.

O grupo foi estruturado com as seguintes características: ser um grupo aberto, sem nenhum critério de exclusão, ou seja, qualquer idoso do centro de convivência poderia participar da oficina, o que levou o grupo a não ter um número fixo de participantes: em média, oito idosos por encontro.

Houve o predomínio de idosos saudáveis com queixas subjetivas de memória. $\mathrm{O}$ gênero predominante foi o feminino, representando $90 \%$ dos participantes. A idade variou entre 60 e 87 anos, predominando idosos acima de 70 anos. 
Seu desenvolvimento deu-se em 13 encontros, com frequência semanal e com aproximadamente uma hora de duração cada, sendo sua divulgação realizada através de cartazes que foram confeccionados e distribuídos pela instituição e por meio de convites feitos pelos funcionários aos idosos frequentadores das diversas atividades propostas no centro de convivência.

Todos os encontros foram documentados em relatórios que descreviam as atividades realizadas, seus objetivos específicos e o desempenho dos participantes, sendo que o último aspecto foi identificado através de observaçôes clínicas, visto que a cada encontro uma das estagiárias era a observadora, não participando das atividades, apenas anotando o que observava do desempenho dos idosos.

No último encontro utilizou-se como método de avaliação um questionário semiestruturado, elaborado pelas estagiárias, contendo questóes sobre a opiniấo dos participantes em relaçáo à qualidade de cada atividade realizada e sobre a percepção de cada participante em relação à existência ou não de mudanças em sua memória com a participação na oficina.

A partir do material coletado foi feita uma análise qualitativa, discutindo-se a percepçáo de desempenho dos participantes com base nos relatos trazidos por eles e nas observaçôes clínicas documentadas nos relatórios. Foi realizada também uma análise quantitativa das avaliaçóes respondidas pelos idosos, qualificando as atividades e a percepçáo dos efeitos observados no desempenho de sua memória após a participaçáo na oficina. Os dados das avaliaçóes foram digitados em planilha do programa Excel 2007 e nele analisados.

\section{Atividades desenvolvidas}

As atividades propostas aos participantes tinham objetivos específicos que estavam relacionados, principalmente, com o estímulo dos subsistemas da memória, outros aspectos cognitivos e aspectos psicossociais.

O Tabela 1 apresenta as atividades, os aspectos estimulados e em quais encontros foram realizadas.

\section{Resultados}

A avaliação semiestruturada, apresentada na Figura 1, contendo questôes referentes à qualidade das atividades e sobre a percepçáo de mudanças na memória com a participação na oficina foi respondida por oito participantes, número correspondente aos idosos presentes no último encontro.
Para a qualificação das atividades realizadas em cada oficina foram oferecidas as opçôes: ruim, regular, bom, muito bom e excelente. Os participantes que responderam a avaliação qualificaram apenas os encontros de que haviam participado. A Tabela 2 apresenta a qualificação atribuída a cada encontro.

Todas as atividades desenvolvidas foram qualificadas entre bom, muito bom e excelente. $\mathrm{O}$ sexto e o $11^{\circ}$ dia de oficina apresentaram melhores qualificaçóes, sendo considerados excelentes por todos os participantes, demonstrando que as atividades realizadas nesses encontros (Memória Sensorial e Perfil Adaptado) foram classificadas como as melhores atividades propostas. $\mathrm{O}$ quarto encontro foi qualificado como bom $(66,66 \%)$ e muito bom $(33,33 \%)$, o que demonstrou que a atividade realizada (Dinâmica das celebridades) foi a de menor preferência dos participantes, mas mesmo assim considerada uma boa atividade por $66,66 \%$ dos participantes.

Em relação à percepção de mudanças em sua memória com a participaçáo na oficina Deu Branco, foram oferecidas as seguintes opções de qualificação: piorou, não mudou nada, melhorou um pouco e melhorou muito. Dois participantes (25\%) responderam que a memória melhorou um pouco e seis participantes $(75 \%)$ responderam que a memória havia melhorado muito.

$\mathrm{Na}$ avaliação havia também um espaço livre para que os participantes escrevessem algumas observações, sugestões, críticas e qualquer outra informação que desejassem apontar. Nesse espaço, outros aspectos estimulados durante as oficinas, como a atenção e a socialização, foram apontados como foco de melhora por $25 \%$ dos participantes.

A participante E. escreveu: "Na verdade, o que mudou foi o meu nível de atenção às coisas que eu faço", e a participante M. escreveu: "Eu participei pouco e com certeza fiquei muito feliz com os encontros. Foram ótimos para a convivência e, claro, ótimos para a memória..."

Através dos relatórios elaborados pelas estagiárias sobre cada encontro foi possível verificar a evolução dos participantes no decorrer da oficina. Segundo a percepção clínica das estagiárias, as atividades propostas contribuíram para melhoria do desempenho cognitivo, psicológico e social dos participantes.

Pode-se observar que dúvidas relacionadas à compreensão das regras das atividades diminuíram conforme a evolução da oficina, demonstrando que os participantes estavam mais atentos durante as explicações, além disso percebeu-se melhoria do desempenho dos participantes durante as atividades, aqueles que realizavam-nas com o auxílio das estagiárias, ao início da oficina, passaram a realizá-las de forma independente ou só com suporte verbal. 
Tabela 1. Atividades realizadas nos encontros, com respectivos objetivos.

\begin{tabular}{|c|c|c|}
\hline $\begin{array}{l}\text { Atividade } \\
\end{array}$ & Aspectos estimulados & Encontro \\
\hline $\begin{array}{l}\text { Nomes e gestos: cada participante disse o seu nome e realizou um gesto, } \\
\text { o participante seguinte repetiu o nome e o gesto que a pessoa anterior } \\
\text { realizou e acrescentou o seu nome e o seu gesto. }\end{array}$ & $\begin{array}{l}\text { Memória de Curto Prazo } \\
\text { e Socialização }\end{array}$ & $1^{\mathrm{o}}$ \\
\hline $\begin{array}{l}\text { Apresentando o seu parceiro: em duplas os participantes relataram um } \\
\text { pouco sobre sua história de vida e ao final cada participante apresentou a } \\
\text { história de vida do outro. }\end{array}$ & $\begin{array}{l}\text { Escuta, } \\
\text { Memória de Curto Prazo } \\
\text { e Socialização }\end{array}$ & $1^{\mathrm{o}}$ \\
\hline $\begin{array}{l}\text { Confecção de crachás: os participantes ficaram livres para decorar e } \\
\text { escrever o seu nome nos crachás. }\end{array}$ & $\begin{array}{l}\text { Dispositivo de auxílio } \\
\text { para a memorização do } \\
\text { nome dos participantes. }\end{array}$ & $1^{\mathrm{o}}$ \\
\hline $\begin{array}{l}\text { Qual é a música? Foram selecionadas músicas referência das décadas } \\
\text { passadas. Os idosos foram estimulados, a partir de um trecho da música, } \\
\text { a identificar o nome da música, o nome do cantor e a continuar a cantá-la } \\
\text { do trecho interrompido. }\end{array}$ & $\begin{array}{l}\text { Memória Episódica, } \\
\text { Memória Semântica, } \\
\text { Atenção, Concentração, } \\
\text { Socialização e } \\
\text { Cooperacão }\end{array}$ & $2^{\circ}$ e $12^{\circ}$ \\
\hline $\begin{array}{l}\text { Jogo de stop: categorias de um determinado tema são dispostas em } \\
\text { colunas, uma letra do alfabeto é sorteada e os participantes completam } \\
\text { as categorias com palavras que iniciem com a letra sorteada. Os temas } \\
\text { selecionados foram Cômodos de uma casa e Locais diversos. }\end{array}$ & $\begin{array}{l}\text { Memória Semântica, } \\
\text { Atenção, } \\
\text { Concentração, } \\
\text { Raciocínio Abstrato e } \\
\text { Cooperação }\end{array}$ & $3^{\circ}$ e $8^{\circ}$ \\
\hline $\begin{array}{l}\text { Dinâmica das celebridades: foram selecionadas imagens de artistas de } \\
\text { diferentes épocas. A cada imagem exposta, os participantes deviam dizer } \\
\text { o nome do artista e algum momento marcante da carreira dele. }\end{array}$ & $\begin{array}{l}\text { Memória Episódica, } \\
\text { Memória Semântica, } \\
\text { Atenção, Concentração, } \\
\text { Raciocínio Abstrato e } \\
\text { Cooperação }\end{array}$ & $4^{\circ}$ \\
\hline $\begin{array}{l}\text { Recordando o caminho de casa: os participantes escreveram o caminho } \\
\text { que realizavam de sua casa até o Cecom Vida Nova, contendo nome das } \\
\text { ruas, pontos de referência e outros detalhes do caminho percorrido. }\end{array}$ & $\begin{array}{l}\text { Orientação } \\
\text { Topográfica, Memória } \\
\text { de Procedimentos e } \\
\text { Raciocínio Abstrato }\end{array}$ & $5^{\circ}$ \\
\hline $\begin{array}{l}\text { Memória sensorial - tato e olfato: foram selecionados alguns alimentos, } \\
\text { condimentos, fragrâncias e objetos, oferecidos para um participante, com } \\
\text { os olhos vendados, por vez. }\end{array}$ & $\begin{array}{l}\text { Memória Sensorial (Tato } \\
\text { e Olfato) }\end{array}$ & $6^{\circ}$ \\
\hline $\begin{array}{l}\text { Novelo de lã: cada participante enrola um pedaço de lã na mão, diz um } \\
\text { alimento que gosta e outro que não gosta e em seguida joga o novelo } \\
\text { para outro participante. Ao final, o último participante deve relembrar } \\
\text { os alimentos que a pessoa anterior falou até que o novelo volte para o } \\
\text { participante que iniciou a atividade. }\end{array}$ & $\begin{array}{l}\text { Memória de Curto } \\
\text { Prazo, Memória } \\
\text { Episódica, Atenção e } \\
\text { Concentração }\end{array}$ & $7^{\circ}$ \\
\hline $\begin{array}{l}\text { Palavras cruzadas: com o tema Alimentos para estimular a memória. Os } \\
\text { participantes responderam as perguntas com dicas sobre esses alimentos. }\end{array}$ & $\begin{array}{l}\text { Memória Semântica, } \\
\text { Atenção, Raciocínio } \\
\text { Abstrato e Socialização }\end{array}$ & $7^{\circ}$ \\
\hline $\begin{array}{l}\text { Imagem e ação: os participantes representaram através de mímica ou } \\
\text { desenho o que estava escrito em cartões. Os cartões continham palavras } \\
\text { separadas por temas: atividades de lazer, atividades básicas da vida diária, } \\
\text { locais e celebridades. Cada participante escolhia um cartão e a forma } \\
\text { como iria representar para seu grupo adivinhar o conteúdo do cartão em } \\
\text { três minutos. }\end{array}$ & $\begin{array}{l}\text { Memória Episódica, } \\
\text { Memória Semântica, } \\
\text { Memória de } \\
\text { Procedimentos, } \\
\text { Compreensão de } \\
\text { Regras, Cooperação e } \\
\text { Socialização } \\
\end{array}$ & $9^{\circ}$ \\
\hline $\begin{array}{l}\text { Jogos variados: Dominó comum, Dominó Palavra Imagem, Jogos da } \\
\text { Memória, Lince, Cara a Cara, } 60 \text { Segundos, Resta } 1 \text { e Dama. Com todos } \\
\text { os jogos dispostos nas mesas, os idosos dividiram-se em grupos e duplas e } \\
\text { escolheram o que gostariam de jogar. }\end{array}$ & $\begin{array}{l}\text { Atenção, Raciocínio } \\
\text { Abstrato, Resolução de } \\
\text { Problemas, Cooperação } \\
\text { e Socialização }\end{array}$ & $10^{\circ}$ \\
\hline $\begin{array}{l}\text { Perfil adaptado: o idoso sorteado fez perguntas para descobrir quem era } \\
\text { a celebridade que estava colada em sua testa, essas perguntas só puderam } \\
\text { ser respondidas pelos demais participantes com sim ou não. }\end{array}$ & $\begin{array}{l}\text { Memória Episódica, } \\
\text { Memória Semântica, } \\
\text { Raciocínio Abstrato, } \\
\text { Percepção, Nomeação, } \\
\text { Atenção e Socialização }\end{array}$ & $11^{\circ}$ \\
\hline $\begin{array}{l}\text { Encerramento: inicialmente foi entregue aos participantes uma avaliação } \\
\text { sobre a qualidade das atividades realizadas e a percepção de mudanças } \\
\text { ou não em relação à memória com a participação na oficina. Em seguida } \\
\text { foram entregues kits de memória, que continham: jogos de stop, jogos de } \\
\text { memória, palavras cruzadas e uma lista com os alimentos que estimulam } \\
\text { a memória. Através de uma confraternização, com a proposta de um café } \\
\text { da tarde, a oficina Deu Branco foi encerrada, relembrando-se as atividades } \\
\text { realizadas e as mudanças ocorridas. }\end{array}$ & $\begin{array}{l}\text { Avaliação e } \\
\text { Confraternização }\end{array}$ & $13^{\circ}$ \\
\hline
\end{tabular}




\section{AVALIACÃO DAS ATIVIDADES REALIZADAS NA OFICINA DEU BRANCO}

\section{PRIMEIRA OFICINA:}

Neste dia foram realizadas 3 atividades:

"Dinâmica de apresentação dos nomes",

"Apresentando o seu parceiro", e

"Confecção dos crachás".

O que você achou das atividades?

Ruim ( ) Regular ( ) Bom ( ) Muito

Bom ( ) Excelente ( )

SEGUNDA OFICINA: Neste dia realizamos 2 atividades: "Qual é a música?"

e Alongamento.

O que você achou das atividades?

Ruim ( ) Regular ( ) Bom ( ) Muito

Bom ( ) Excelente ( )

\section{TERCEIRA OFICINA:}

Neste dia realizamos o Jogo de Stop sobre os cômodos de uma casa.

$\mathrm{O}$ que você achou das atividades?

Ruim ( ) Regular ( ) Bom ( ) Muito

Bom ( ) Excelente ( )

\section{OUARTA OFICINA:}

Neste dia realizamos a atividade "Dinâmica das celebridades".

O que você achou das atividades?

Ruim ( ) Regular ( ) Bom ( ) Muito

Bom ( ) Excelente ( )

\section{OUINTA OFICINA:}

Neste dia realizamos a atividade

"Recordando o caminho de casa".

O que você achou das atividades?

Ruim ( ) Regular ( ) Bom ( ) Muito

Bom ( ) Excelente ( )

\section{SEXTA OFICINA:}

Neste dia realizamos 2 atividades: a "Oficina do olfato e tato" e Alongamento.

$\mathrm{O}$ que você achou das atividades?

Ruim ( ) Regular ( ) Bom ( ) Muito

Bom ( ) Excelente ( )

\section{SÉTIMA OFICINA:}

Neste dia realizamos 2 atividades:

"Dinâmica do novelo de lã" e "Palavra

cruzada com os alimentos que estimulam a memória".

O que você achou das atividades?

Ruim ( ) Regular ( ) Bom ( ) Muito

Bom ( ) Excelente ( )

\section{OITAVA OFICINA:}

Neste dia realizamos o Jogo de Stop sobre lugares (Shopping, fazenda, praia, rua e clube).

O que você achou das atividades?

Ruim ( ) Regular ( ) Bom ( ) Muito

Bom ( ) Excelente ( )

\section{NONA OFICINA:}

Neste dia realizamos a atividade "Imagem e Ação".

O que você achou das atividades?

Ruim ( ) Regular ( ) Bom ( ) Muito

Bom ( ) Excelente ( )

DÉCIMA OFICINA:

Neste dia realizamos a atividade "Oficina de Jogos".

O que você achou das atividades?

Ruim ( ) Regular ( ) Bom ( ) Muito

Bom ( ) Excelente ( )

\section{DÉCIMA PRIMEIRA OFICINA:}

Neste dia realizamos a atividade "Jogo do Perfil de um Artista".

O que você achou das atividades?

Ruim ( ) Regular ( ) Bom ( ) Muito

Bom ( ) Excelente ( )

\section{DÉCIMA SEGUNDA OFICINA:}

Neste dia realizamos a atividade "Qual é a música?".

O que você achou das atividades?

Ruim ( ) Regular ( ) Bom ( ) Muito

Bom ( ) Excelente ( )

Agora gostaríamos que você respondesse se houve alguma mudança, principalmente na sua memória, depois que começou a participar da Oficina Deu Branco?

Piorou ( )

Não mudou nada ( )

Melhorou um pouco ( )

Melhorou muito ( )

Deixamos esse espaço para você escrever outras observações, sobre o nosso comportamento, sugestões, críticas e qualquer outra informação que você deseja nos dizer.

Figura 1. Questionário semiestruturado aplicado aos participantes para a avaliação da oficina Deu Branco. 
Tabela 2. Qualificação das atividades realizadas na oficina Deu Branco.

\begin{tabular}{cccccc}
\hline Encontro & Ruim & Regular & Bom & Muito bom & Excelente \\
\hline $\mathbf{1}^{\mathbf{0}}$ & $0 \%$ & $0 \%$ & $0 \%$ & $33,33 \%$ & $66,66 \%$ \\
$\mathbf{2}^{\mathbf{o}}$ & $0 \%$ & $0 \%$ & $33,33 \%$ & $33,33 \%$ & $33,33 \%$ \\
$\mathbf{3}^{\mathbf{0}}$ & $0 \%$ & $0 \%$ & $20 \%$ & $20 \%$ & $60 \%$ \\
$\mathbf{4}^{\mathbf{0}}$ & $0 \%$ & $0 \%$ & $66,66 \%$ & $33,33 \%$ & $0 \%$ \\
$\mathbf{5}^{\mathbf{0}}$ & $0 \%$ & $0 \%$ & $0 \%$ & $33,33 \%$ & $66,66 \%$ \\
$\mathbf{6}^{\mathbf{0}}$ & $0 \%$ & $0 \%$ & $0 \%$ & $0 \%$ & $100 \%$ \\
$\mathbf{7}^{\mathbf{0}}$ & $0 \%$ & $0 \%$ & $20 \%$ & $0 \%$ & $80 \%$ \\
$\mathbf{8}^{\mathbf{o}}$ & $0 \%$ & $0 \%$ & $0 \%$ & $25 \%$ & $85 \%$ \\
$\mathbf{9}^{\mathbf{0}}$ & $0 \%$ & $0 \%$ & $20 \%$ & $0 \%$ & $80 \%$ \\
$\mathbf{1 0}^{\mathbf{0}}$ & $0 \%$ & $0 \%$ & $0 \%$ & $37,5 \%$ & $62,5 \%$ \\
$\mathbf{1 1}^{\mathbf{0}}$ & $0 \%$ & $0 \%$ & $0 \%$ & $0 \%$ & $100 \%$ \\
$\mathbf{1 2}^{\mathbf{0}}$ & $0 \%$ & $0 \%$ & $14,28 \%$ & $42,85 \%$ & $42,85 \%$ \\
\hline
\end{tabular}

Foi possível identificar, pela observação clínica, a evolução de E1, 70 anos, que sofreu um Acidente Vascular Encefálico, há dois anos. No início da oficina, E1 demonstrava muita dificuldade com relação à linguagem (expressão) e à memória episódica. No decorrer dos encontros, E1 participou de $12 / 13$, passou a se comunicar melhor de forma verbal e também teve uma participação mais efetiva nas atividades, recordando-se do que era solicitado, no início com suporte, mas ao final de forma independente.

Com relação aos aspectos psicossociais, cabe ressaltar que os participantes apresentaram boa interação, além de cooperarem uns com os outros, mesmo quando a atividade em questão era uma competição, e passaram a ter uma participação mais efetiva, tornando-se mais comunicativos.

\section{Discussão}

A elaboração da oficina Deu Branco e a formação de um grupo foram os primeiros desafios encontrados. Apesar de se tratar de um grupo aberto que teve presença variável, porém constante por parte de alguns participantes, os resultados foram positivos, tanto para os idosos como na formaçấo das estagiárias.

Alguns estudos demonstram que intervençôes utilizando-se de técnicas de memorização, relaxamento e atenção promovem efeitos positivos e prolongados em idosos, principalmente quando são aplicadas em grupos (YASSUDA, 2002). Além disso, segundo Guerreiro (2001), a estimulação continuada promove a vivacidade mental, prevenindo o declínio cognitivo, pois essa estimulação tem relação direta com o desempenho cognitivo.

Os idosos que ingressaram na oficina relataram no início queixas subjetivas de perda de memória, justificando assim seu interesse em participar. Estudo realizado com idosos ingressantes em oficinas de memória identificou alta prevalência de queixas de memória entre os participantes e aponta que a preocupação com o desempenho cognitivo é uma característica entre aqueles que buscam treinamento de memória. Além disso, um grande número de pesquisas vem sugerindo que a percepção subjetiva de perda de memória, quando associada a outros critérios, pode contribuir para identificação de sujeitos que apresentam prejuízo cognitivo, sendo necessário um olhar mais atento às queixas de grande número de idosos que procuram oficinas para o treinamento da memória (GUERREIRO et al., 2006).

$\mathrm{Na}$ oficina Deu Branco, o gênero predominante foi o feminino, representando $90 \%$ dos participantes, e a idade variou entre 60 e 87 anos, predominando idosos acima de 70 anos. Segundo Jonker, Geerlings e Schmand (2000) em um estudo de revisão internacional, a idade avançada, o sexo feminino e baixo nível de escolaridade estấo associados à alta prevalência de queixas de memória.

O número elevado de mulheres participantes na oficina, além de correlacionar-se com o processo de feminização da velhice, demonstrou uma maior participação das mulheres em atividades fora do ambiente domiciliar, o que já era de se esperar, visto que as mulheres, mais do que os homens, participam de atividades extradomésticas como organizaçôes e movimentos de mulheres, cursos, viagens, trabalhos voluntários e trabalhos remunerados temporários (CAMARANO, 2006).

As atividades desenvolvidas foram elaboradas e propostas considerando as demandas e características do grupo, o perfil social, cultural, cognitivo, emocional e funcional dos participantes, objetivando assim um maior interesse e envolvimento dos partícipes nas atividades propostas e, consequentemente, uma boa adesão à oficina. 
Através da análise da atividade, técnica utilizada pelos terapeutas ocupacionais, é possível identificar as demandas da atividade, os componentes de desempenho necessários e os significados culturais atribuídos a determinadas atividades e, com isso, selecioná-las, adaptá-las e graduá-las de forma a alcançar os objetivos pretendidos (CREPEAU, 2002).

Ao término dos 13 encontros, através da análise dos relatórios elaborados, da avaliaçáo semiestruturada e da percepção clínica, obtida através da observação do desempenho dos participantes pelas estagiárias, pôde-se observar que as atividades propostas contribuíram para a melhoria do desempenho cognitivo, psicológico e social durante os encontros e, além disso, foram bem qualificadas pelos participantes.

Os resultados obtidos foram baseados na percepção tanto dos idosos quanto das estagiárias, portanto tratam-se de opinióes construídas e elaboradas durante a realização dos encontros, que embora subjetivas, pois cada um se percebe e percebe o outro de modo diferente, são significativas e importantes. Segundo Iervolino e Pelicioni (2001), pesquisas internacionais em saúde realizadas nas últimas décadas ressaltam a importância dos procedimentos qualitativos como fundamentais para verificar como as pessoas avaliam uma experiência, ideia ou evento, quais opiniôes, sentimentos e significados estão associados a determinado acontecimento.

Almeida, Beger e Watanabe (2007) elaboraram uma proposta de oficina para o treinamento de memória como promoção de saúde da populaçáo idosa e evidenciaram em suas conclusóes que os resultados obtidos basearam-se na percepção dos idosos, que pode ser influenciada por fatores como humor e pressóes sociais mas é um elemento importante para a compreensáo da realidade vivenciada por eles e, consequentemente, para a repercussão dessas questôes na vida cotidiana.

Estudo realizado por Ball et al. (2002) demonstrou que o treino cognitivo de 11 seçóes pode gerar melhora significativa em idosos, particularmente em habilidades como velocidade de processamento, raciocínio indutivo e memória. Foi evidente, através da percepção clínica, a melhora da memória nos três estágios básicos do processamento da informação (codificação, armazenamento e resgate da informação). No decorrer dos encontros, os idosos passaram a responder ao que era solicitado com mais rapidez (diminuição do tempo de resposta) e facilidade (resgate de informação), além de relacionarem determinados assuntos com histórias pessoais. A oficina visou estimular não apenas os subsistemas da memória mas também outros aspectos cognitivos que contribuem para o melhor desempenho cognitivo.
A oficina demonstrou ser um espaço de socialização entre os participantes, com a criação de laços de amizade, momentos de descontração e lazer, proporcionando sentimentos de utilidade e valorização das potencialidades dos indivíduos. Vistos os benefícios das oficinas, alguns autores reforçam a necessidade da manutençáo dos grupos existentes e da criaçáo de novos visando um maior número de idosos e comunidades que não dispóem desses serviços (JOÃO et al., 2005; ARAÚJO; COUTINHO; CARVALHO, 2005).

A falta da aplicação de avaliaçóes padronizadas para identificar o desempenho cognitivo dos idosos antes e após a participação na oficina foi uma das limitaçôes encontradas, porém destaca-se que esse não era o objetivo do trabalho, uma vez que tratava-se de um grupo aberto, o que dificulta a comparação antes e após a intervenção.

Para futuros estudos sugere-se a aplicação de instrumentos que avaliem o desempenho objetivo e subjetivo dos componentes cognitivos antes e após a realização da oficina a fim de comparar tais resultados e verificar de maneira quantitativa o desempenho dos participantes. Vale ressaltar a importância de mantermos avaliaçóes subjetivas de memória, somando-se assim as percepçôes dos participantes aos dados objetivos de desempenho, em uma abordagem qualiquantitativa para a confirmação ou não da melhora no desempenho.

\section{Considerações finais}

A oficina Deu Branco representou uma possibilidade de intervenção cognitiva, psicológica e social, apresentando-se como proposta de intervenção na promoção e prevençáo da saúde dos idosos frequentadores dos centros de convivência para a terceira idade.

A estrutura e a dinâmica das atividades possibilitaram a interação dos participantes, momentos de descontraçáo e lazer, contribuindo para a estimulação de funçóes cognitivas, bem como para o aumento das redes de suporte social dos idosos, segundo a observação clínica das estagiárias.

Pensando na promoção e prevenção em saúde como um objetivo terapêutico ocupacional no envelhecimento, as oficinas de memória nos centros de convivência para a terceira idade podem se tornar um recurso economicamente viável e uma forma de intervenção precoce junto a essa população.

\section{Referências}

ABREU, V. P. S.; TAMAI, S. A. B. Reabilitação Cognitiva em Gerontologia. In: FREITAS, E. V. et al. Tratado de 
Geriatria e Gerontologia. Rio de Janeiro: Guanabara Koogan, 2006. p. 1162-1169.

ALMEIDA, M. H. M.; BEGER, M. L. M.; WATANABE, H. A. W. Oficina de memória para idosos: estratégia para promoção da saúde. Interface: Comunicação, Saúde, Educação, Botucatu, v. 11, n. 22, p. 271-280, 2007. http://dx.doi.org/10.1590/S1414-32832007000200007 ARAÚJO, L. F.; COUTINHO, M. P. L.; CARVALHO, V. A. M. L. Representaçóes sociais da velhice entre idosos que participam de grupos de convivência. Psicologia, Ciência e Profissão, Brasília, v. 25, n. 1, p. 118-131, 2005.

BALL, K. et al. Effects of cognitive training interventions whit older adults: A randomized controlled trial. Journal of the American Medical Association, Chicago, v. 288, n. 18, p. 2271-2281, 2002.

BRASIL. Portaria MPAS/SEAS no 73. Normas de Funcionamento de Serviços de Atenção ao Idoso no Brasil. Brasília: Ministério da previdência e Assistência Social, 2001

CAMARANO, A. A. Envelhecimento da População Brasileira: Uma Contribuição Demográfica. In: FREITAS, E. V. et al. Tratado de geriatria e gerontologia. Rio de Janeiro: Guanabara Koogan, 2006. p. 1172-1179.

CARTILHA Condominio Solidário. [s.1.: s.n.], 2011. Disponível em: <http://www.santos.sp.gov.br>. Acesso em: 03 ago. 2011.

CREPEAU, E. B. Análise de atividades: uma forma de refletir sobre desempenho ocupacional. In: NEISTADT, M. E.; CREPEAU, E.B. Willard \& Spackman: Terapia Ocupacional. Rio de Janeiro: Guanabara Koogan, 2002. p. 121-133.

GUERREIRO, T. Oficina de Memória. Uma proposta de otimização cognitiva para idosos. In: GUERREIRO, T.; CALDAS, C. P. C. Memória e demência: (re) conhecimento e cuidado. Rio de Janeiro: UERJ, 2001. p. 9-127.

GUERREIRO, T. C. et al. Queixas de memória e disfunção de memória em idosos que ingressal na Oficina da Memória na UnATI/UERJ. Revista Brasileira de
Geriatria e Gerontologia, Rio de Janeiro, v. 9, n. 1, p. 7-20, 2006.

IERVOLINO, S. A.; PELICIONI, M. C. F. A utilização do grupo focal como metodologia qualitativa na promoção da saúde. Revista da Escola de Enfermagem USP, Sáo Paulo, v. 35, n. 2, p. 115-21, 2001. http://dx.doi.org/10.1590/ S0080-62342001000200004

INSTITUTO BRASILEIRO DE GEOGRAFIA E ESTATÍSTICA - IBGE. Sintese de Indicadores Sociais 2010. Rio de Janeiro: IBGE, 2010. Disponível em: <http:// www.ibge.gov.br>. Acesso em: 30 jul. 2011.

JOÃO, A. F. et al. Atividades em Grupo-alternativa para minimizar os efeitos do envelhecimento. Textos sobre Envelhecimento, Rio de Janeiro, v. 8, n. 3, p. 397-410, 2005.

JONKER, C.; GEERLINGS, M. I.; SCHMAND, B. Are memory complaints predictive for dementia? A review of clinical and population-based studies. Journal of Geriatric Psychiatry, Madison, v. 15, n. 11, p. 983-991, 2000. http:// dx.doi.org/10.1002/1099-1166(200011)15:11<983::AIDGPS238>3.0.CO;2-5

LIMA, L. J. C.; PASETCHNY, N. Atividades em grupo: uma alternativa para a inclusão social na terceira idade. Revista Terapia Ocupacional da Universidade de São Paulo, São Paulo, v. 9, n. 1, p. 37-42, 1998.

MELLO, M. A. F. Terapia Ocupacional Gerontológica. In: CAVALCANTI, A.; GALVÃO, C. Terapia ocupacional: Fundamentação e Prática. Rio de Janeiro: Guanabara Koogan, 2007. p. 367-376.

PAPÁLEO NETTO, M. P. Processo de Envelhecimento e Longevidade. In: PAPÁLEO NETTO, M. P. Tratado de Gerontologia. São Paulo: Atheneu, 2007. p. 3-14.

SANTOS. Prefeitura municipal. [s.l.: s.n.], 2010. Disponível em <http://www.santos.sp.gov.br>. Acesso em: 02 jul. 2010. YASSUDA, M. S. Memória e Envelhecimento Saudável. In: FREITAS, E. V. et al. Tratado de Geriatria e Gerontologia. Rio de Janeiro: Guanabara Koogan, 2002. p. 914-919.

\section{Contribuição dos Autores}

Todas as autoras estiveram envolvidas na experiência apresentada, sendo Márcia Novelli a orientadora. Todas as autoras estiveram envolvidas na redação do manuscrito e aprovaram sua versão final. 